\title{
GEOLOGICAL AND LITHOLOGICAL MAPPING OF PART OF IGARRA SCHIST BELT USING INTEGRATED GEOPHYSICAL METHODS
}

\author{
Ademila, 0, Okpoli, C.C*, Ehinmitan, D \\ Department of Earth Sciences, Adekunle Ajasin University, PMB 1, Akungba-Akoko, Ondo State, Nigeria. \\ *Corresponding Author E-mail: cyril.okpoli@aaua.edu.ng
}

This is an open access article distributed under the Creative Commons Attribution License, which permits unrestricted use, distribution, and reproduction in any medium, provided the original work is properly cited.

\section{ARTICLE DETAILS}

Article History:

Received 18 July 2018

Accepted 29 September 2018

Available online 18 January 2019

\section{ABSTRACT}

Integrated geophysical techniques involving magnetic and radiometric data were used to investigate the subsurface geometry of Igarra schist belt in Precambrian basement complex of southwestern Nigeria which falls within the latitude range of $7^{\circ} 1635.6^{\prime \prime}$ to $7^{\circ} 1736.0^{\prime}$ North and longitude range of $6^{\circ} 0534.1^{\prime \prime}$ to $6^{\circ} 05^{\prime} 44^{\prime \prime}$ East, with a view to interpret the geology of part of Igarra schist belt and estimate the depth to basement of magnetic source in the area. Six profiles were established with the objective of delineating the metasediments and its structural attributes, and geophysical measurements were made at $5 \mathrm{~m}$ intervals along these profiles. The results of magnetic datasets were presented as maps and profiles of varying magnetic intensities and the causative rock types. Qualitative interpretation of the magnetic data using Reduction to pole, Analytical signal, first vertical, horizontal and tilt derivatives, upward continuation filters shows what has been interpreted as the signature of a near-vertical fault, trending along a NE-SW and NW-SE direction while radiometric datasets gave geochemical rates of $\mathrm{U}$, Th and $\mathrm{K}$ as well as the effect of water contents on the rocks present within the study area. Qualitative and quantitative interpretation of individual magnetic anomalies and geological knowledge of the survey area yielded information on the depth of the geological features (e.g. rock contact, faults or fractures), structure and magnetic properties of rock units. 3D Euler deconvolution and Average radial spectrum were adopted to estimate the depth of the magnetic sources which ranges from - $92.895 \mathrm{~m}$ to $73.95 \mathrm{~m} ;-115.45 \mathrm{~m}$ to $57.44 \mathrm{~m}$ and $63 \mathrm{~m}$ to $44.1 \mathrm{~m} ; 88.2 \mathrm{~m}$ to $81.9 \mathrm{~m}$ respectively. The Igarra schist belt has evolved different episodes of orogenies and the metasediments were formed from low grade regional metamorphism of argillaceous sediments such as shales or sediments of varying composition.

\section{KEYWORDS}

Magnetic, Radiometric, Igarra Schist-belt, Qualitative and quantitative interpretations.

\section{INTRODUCTION}

Based on a study, ground magnetic study is used for detail mapping in order to understand the subsurface geology of an area [1]. According to a scholar, it has been used extensively in basement mapping [2]. The use of integration of geophysical methods such as radiometric, electromagnetic and magnetic techniques as a geological and lithological mapping instruments have been confirmed by numerous authors [3,4].The technique requires measurements of the amplitude of magnetic components at discrete points along traverses distributed regularly throughout the survey area of interest. In ground magnetic study, three components are measured which are horizontal, vertical and total components. The vertical components and the total components are mostly used in the past studies to delineate faults, fractures, depth to magnetic basement and other geological structures. In this study, Total Magnetic Intensity (TMI) or total components were measured at discrete points along traverses in order to investigate on the geologic features like fault, fracture and rock contact distribution within the study area.

The basic purpose of radiometric survey is to determine either the absolute or relative amounts of $\mathrm{U}$, Th., and $\mathrm{K}$ in the surface rocks and soils. These three radioisotopes are naturally found in most rock types and they are of importance in geologic mapping and mineral exploration [5]. In this study radiometric survey proved valuable in delineating the various lithologies within the Igarra schist belt. Hence, this research work is aimed at investigating ground magnetic and radiometric data to study the major surface and subsurface structures, and their relationship with surface structural features in the study area.

\section{SITE DESCRIPTION AND GEOLOGICAL SETTING}

Igarra area is located along Auchi-Ibilo road at a Latitude of 7.33784 North and Longitude of 6.13970 East. It is a town located in the Northern part of Edo-state, Nigeria (Fig.1 a and b). Its topography is mountainous and situated in the lee-wind side of the kukuruku-hill with an area of $1371 \mathrm{~km}$ Igarra area, lies within the southwestern Nigerian basement which itself is a part of the Nigerian Basement Complex. The Nigerian Basement Complex is also a part of the Pan African mobile belt that lies between the West African craton to the east and the Congo craton to the southwest within the African continent. Most parts of the study area is underlain by the metasediments, referred to as the Igarra Schist Belt, which presumably overlies an older gneiss-migmatite basement, possibly of Liberian age [6] The metasedimentary succession in Igarra area consists predominantly of pelitic to semi-pelitic rocks of low to medium grade metamorphism. Major rock types exposed in the area include (i) semi-pelitic phyllites; (ii) quartzbiotite schist; (iii) mica schist; (iv) calc-silicate gneiss and marble; and (v) meta-conglomerate; all of which have been deformed in at least two episodes [7]. These supracrustal rocks and the underlying basement were subsequently intruded by Pan African granites such as the Igarra batholiths and other minor intrusive including pegmatite, aplite, dolerite, lamprophyre and syenite. Small bands of green amphibolitic rocks have been observed to be interbanded with some of the aforementioned main rock units that constitute the schist belt. There are sulphide mineralization hosted by the pelitic to semi-pelitic rocks.

The metasedimentary suite has been intruded by igneous rocks of Pan African age in the study area. Igarra/Semorika pluton is the largest body 
along the southern margin of the belt. Large bodies of the pluton have roof pendants and xenoliths of metasedimentary rocks. Metasedimentary xenoliths are rotated and abundant in the western margin of the pluton. Dykes of granite, syenite, lamprophyre are observed in several parts of the schist belt. The contacts between some of them and the metasedimentary country rocks have undergone contact metamorphism (i.e. granite dyke western part of Igarra). The metasedimentary suite of the Igarra schist belt has been subjected to Greenschist (Barrovian-type) metamorphism, reaching lower Amphibolites facies in some places.

The upper limit of the regional metamorphism is observed by the occurrence of garnet- Staurolite bearing assemblages in pelitic rocks. Towards south of Igarra are the superimposition of effects of contact metamorphism on the regional metamorphic mineral assemblages. The effects of contact metamorphism is widespread in and around Sebe- Ogbe in the form of oavl spots 1 to 1.5 centimetres across the Phyllite and mica schist> the spots consist of quarts and randomly oriented lathes of muscovite, are less resistant to weathering than the rocks in which are occurred, so that differential weathering gives outcrop surface pitted appearance. Close to the contact near south of Sebe-Ogbe-Otuo road and Ikpeshi ovoid spots and rectangular shaped porphroblasts of Cordierite and Andalusite. Structurally, Igarra schist belt are strongly deformed, relic sedimentary structures preserved in several places. For instance, the $2 \mathrm{~km}$ Northeast of Ikpeshi, here each of the five to six units (0.5 meter thick) exposed has a top of metaconglomerate. The clasts range from pebble -size to cobble-size, then finer downward into coarse-sand to fine-sand sizes. The units may also vary from coarse-sand size to fine-sand size elsewhere and sequences are stratigraphically overturned. Effects of ductile deformation resulted to the formation of : small-scale folds of various sizes and styles; axial plane schistosity, cleavage; cleavage refraction due to contrast in competence between alternating layers, strain-slip cleavages from later deformation, interference patterns due to superimposed deformation; transportation fabrics, which tends to destroy earlier structures. Effects of later semi-brittle to brittle deformation which have in various localities resulted to fault breccias, shear zones and sigmoidal tension gashes. Different types of foliations are: lithologic banding at Ojirami-Peteshi on scale of centimeters to few of centimeters; mineralogical banding on scale of few millimeters known as $\mathrm{S}_{0} / \mathrm{S}_{1}$ fabric; axial plane schistosity/cleavage concomitant with folding and refraction at alternating lithologies due to competence contrast; strain-slip crenulation cleavage which resulted to sigmoidal, fault-like fabric. Lineation resulted into mullions- produced by thickening and elongation of minor fold hinges in quartzite. Intersection of two plane fabric: So/S fabric and $S_{2}$ axial plane cleavage. Lineation from the intersection of $S_{2}$ on So/ $\mathrm{S}_{1}$ and $\mathrm{L}_{2}$ from the intersection of So/ $\mathrm{S}_{1}$ on $\mathrm{S}_{2}$. Transposition fabrics due to tightening rotation of the fold hinges with attenuation and eventual obliteration of the limbs. The effects of later brittle to semi-brittle deformation abound in the study area. Normal and reverse fault of the order tens of centimeters; fault breccias in the Northern part of Igarra i.e East-West strike-slip faults; sigmoidal tension gashes due to orientation of stress field during the shearing movement; shear zones- structural, semibrittle shear zone is about 0 metres which has dragged down the preexisting foliation of quartzite to near vertical orientation.

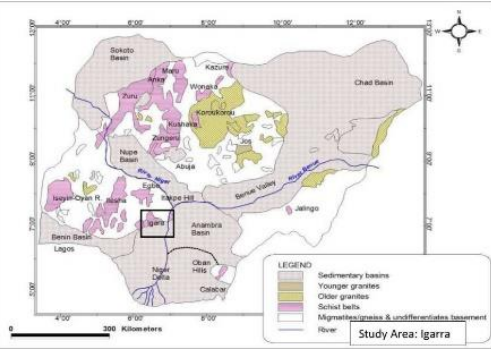

Figures 1 (a): Generalized Geological map of Nigeria

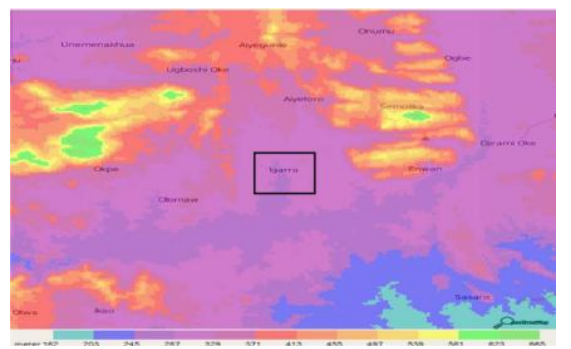

Figures 1(b): Elevation map of Igarra (FloodMap.net)

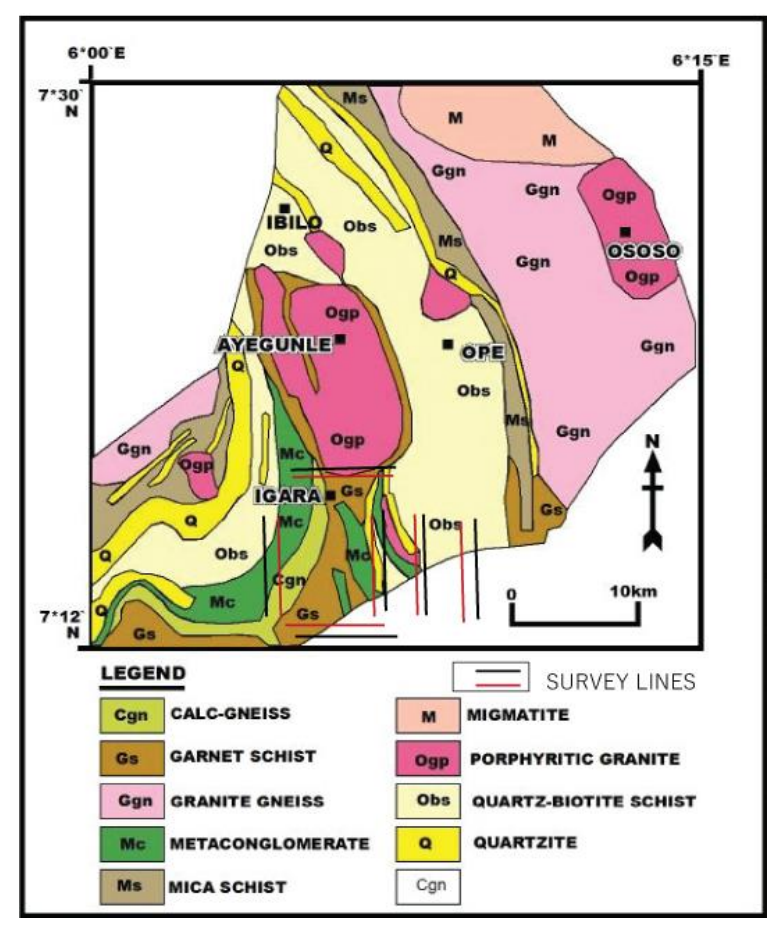

Figure 2: Geological Map of the Study Area and Environs

\section{METHODOLOGY}

The ground magnetic and radiometric measurements in the survey area were made with a GSM-19T Proton Precession magnetometer and the Gamma Surveyor for the magnetic and radiometric field measurements measuring tape and an e-trex Garmin ${ }^{\mathrm{TM}}$ GPS respectively. The magnetometer measures the absolute value of the total magnetic field strength and six profiles were established perpendicular to the prevailing regional strike of the weak zone (ISZ) being delineated. The locations of these profiles were constrained by the available geological data, mainly lithologic rock boundaries and past work.

The magnetic measurement grid was closed by establishing base measurement points outside each profile; repeat magnetic readings were taken at these survey points before and after measurements were made on profiles $1,2,3,4,5$ and 6 , respectively (Figure 2 - this figure show the location of the profiles). This was done with the purpose of carrying out drift and/or diurnal corrections on the magnetic data recorded. According to a research, the variation of Earth's magnetic field with time, which may last several hours to one day, is called diurnal variation [8]. The detected diurnal variation was removed from our data from the observed drift in the magnetic reading. Five repeat magnetic readings and time observation were inputted at $5 \mathrm{~m}$ intervals along each profile. In order to remove magnetic noise and diurnal magnetic variation from the data obtained, the magnetic data were filtered using a three point moving technique [9]. Noise due to secular variation was considered very negligible because the measurement time was less than two hours for each profile line. After the diurnal correction and filtering were carried out, the next stage of magnetic reduction was to calculate the anomalous geomagnetic field. The Earth's normal magnetic field was calculated through IGRF (the known regional geomagnetic field of 32,000 nT for Igarra area) and subtracted from the diurnal- corrected observed value to produce the residual geomagnetic field. The corrected geomagnetic field data are presented as profiles for the six profiles (see Figure 2 for location). The anomalous geomagnetic field data were plotted on the vertical axis, and the station position on the horizontal axis. Both qualitative and quantitative interpretation of the reduced geomagnetic field was subsequently evaluated using Oasis Montaj ${ }^{\mathrm{TM}}$, Excel and Surfer softwares. The accuracy of the Proton Precession Magnetometer reading is $\pm 1 \mathrm{nT}$, while that of the reduced anomalies is $\pm 5 \mathrm{nT}$.

However, in order to establish the cause of the anomalies observed from the reduced magnetic data, the data were inverted for several geophysical models as well as for structures, using the Geosoft ${ }^{\circledR}$ software package and the images produced were exported in the Jpeg high quality format. Gridding the data provided a way for the application of filters since filtering requires equally spaced data points. All the enhancement techniques were performed with the Geosoft ${ }^{\circledR}$ (Oasis montaj 7.3) The MagMap extension in Geosoft $\AA$, which offers a number of utilities for processing of magnetic data, was used. The necessary filters were applied 
and it was displayed as an image using the grid and image tool. TwoDimensional Fast Fourier Transformation (2D-FFT) filters were applied to enhance the quality of the data. The 2D-FFT filters used included Reduction to the Pole, First Vertical and Horizontal Derivatives, Downward and Upward Derivative, and Analytic Signal. Since one of the axioms of the Fourier domain processing is that the signal must be periodic. And in order to mimic periodicity in the pre-processing stage, the grid was extended to be continuous along both coordinates. The Geosoft oasis montaj Euler3D and radial average power spectrum of the Magmap tool was used to estimate the depth to basement of the magnetic body. This is one of the most cost-effective and rapid techniques for geochemical mapping of the radioactive elements: potassium, uranium and thorium. The interpretation of the images produced such as Ternary Image, Ratio Maps, Potassium and Thorium and Uranium Maps describes briefly some enhancing techniques which were applied on the radiometric dataset. The goal is to recognize and understand radiometric signatures associated with the host rocks important to mineralization.

We employed the Grid and Image tool in Geosoft巴 software, the total count image was created after micro-levelling the entire data set to remove any apparent residual errors. These images were generated by employing mini-curvature gridding since the data were collected in grid window with the grid depending on the images were then correlated with the geological units, patterns and trends. Thorium is generally considered very immobile [10]. A scholar refers to a decrease in Th and an increase in $\mathrm{K}$ for the alteration environment in variety of ore deposits [11].

A ternary RGB colour model was created using Geosoft $\AA$ software for which potassium, thorium and uranium were assigned to the red, green and blue respectively because the blue tends to reduce the poorest signalto-noise ratio of uranium channel. A histogram equalization to give the best colour variation was used to enhance the contrast of the individual histograms of $\mathrm{K}$, Th and $\mathrm{U}$ before combining to composite image

\section{RESULTS AND DISCUSSION}

\subsection{Magnetic anomalies}

\subsubsection{Locations 1 and 2}

The TMI image show high magnetic susceptible areas in low magnetic values (blue) while less magnetic susceptible areas are depicted as high magnetic values (pink colour) except for the analytical signal image and reduction to the pole image where high magnetic susceptible areas are shown as high anomalies. Total magnetic intensity level in the study area ranges from -6.192 to $6.582 \mathrm{nT}$ with the mean value of $-0.067 \mathrm{nT}$ while location 2 ranges from -9.005 to $7.003 \mathrm{nT}$. High anomalies were observed which may be attributed to the presence of basic rocks and rocks rich in iron oxide (biotite-schist, quartzite and meta-conglomerate). Negative anomalies were observed in the area which may be due to the present of low magnetic rocks or felsic rich content (e.g shale, sandstone, weathered sediments) in the area, that are noted for low magnetic signatures. The total magnetic field intensity data was gridded using the minimum curvature method (Fig.3). To highlight the appearance of anomalies near surfaces, the colour-shade grid with illumination inclination of $45^{\circ}$ and declination at $45^{\circ}$ was applied. The total magnetic image showed the difference in locations of high and low magnetic intensities (Fig.3). It also shows the difference in locations of high and low magnetic intensities and many crustal magnetization patterns. The TMI map displays different regional magnetic zones (A, B, C, D, E, H and I in Fig.3a and b) respectively, with most of them trending in the north-south direction and some been polygon features in the south-east part of the image. The magnetic zone division was based on the intensity, shape, and pattern in magnetic signatures. At the eastern corner, there exists a high magnetic signature zone with amplitude range between -6.192 to -2.518 (H Fig.3a), which is cut by low magnetic signature with amplitude range of 4.151 to 6.582 (A Fig. 3a) while in location 2 the high magnetic susceptible body, $(\mathrm{A}$ and $\mathrm{H})$ in the North-west to South-east direction(NW-SE) observed with amplitude range of $(2.012-7.003 \mathrm{nT})$ in Fig. 3b interpreted as the calcgneiss and magnetic anomaly $(\mathrm{B}, \mathrm{C}, \mathrm{G})$ and $0.017-2.012 \mathrm{nT}$ likely represents meta-conglomerate and quartzite based on the classification of magnetic susceptibility of rocks which are known for its relatively high magnetite content respectively. From the TMI image, the high magnetic susceptible body, $(\mathrm{H})$, observed at the lower left corner of Figure $3 \mathrm{a}$ is interpreted as the meta-sedimentary rock which are known for its relatively high magnetite content $[13,15]$. Relatively low magnetic signature (C and D in Fig. 3a) with intensities ranging between 0.190 to $0.816 \mathrm{nT}$ suggests the presence of shale) while location 2) low magnetic anomaly (E) was observed in the western part of the map (Fig.3b). The structures F-F' and S-S' representing likely faults with amplitude intensity of $(-1.703$ to $-3.249 \mathrm{nT}$ and -9.055 to $-2.976 \mathrm{nT})$ respectively.

\subsection{Reduction to pole}

The RTP magnetic anomaly map (Fig. 4) shows both low and high magnetic frequencies representing points of low and high magnetic signatures respectively in the area. Both TMI (Fig.3a and b) and the reduction to the pole RTP image (Fig. 4a and b) display similar magnetic features, but in the RTP image the highs (pink colour) of the TMI are seen as lows (blue colour). The RTP map shows more significant features such as structures and lithology in the magnetic signature than the total magnetic intensity map. Some features such as the low magnetic signature $(\mathrm{A}, \mathrm{B}, \mathrm{C}, \mathrm{E}, \mathrm{J}, \mathrm{K})$ with amplitude range between $(0.013-10.469 \mathrm{nT}$ and high magnetic signature at the bottom and top left corner (South-west, Southeast and North-west as well as (South-west, North-east and North-west) respectively of the image with amplitude range between ( -16.920 to $2.558 \mathrm{nT}$ and ( -24.858 to $-4.076 \mathrm{nT})$ are not clearly seen and amplitude range are lesser in the TMI image but are clearly seen in the RTP. Another distinct feature is the linear magnetic signature (A in Fig. 12) trending in the NE-SW direction (Fig 4b). Also observed are some high (pink) features in the TMI image which remained high (pink) in the RTP image. Example is the magnetic signature (A and L in fig.4a) found at the central and southwestern part of the area while the highest magnetic intensity at the western part of the area (A in Fig. $4 \mathrm{~b}$ ) with the average peak to peak at about $6.522 \mathrm{nT}$. Clear lithological boundaries are also observed in the image. These boundaries are observed from the sharp contrast in the magnetic signature on adjacent magnetic bodies. The high frequency magnetic anomaly at the western part of the area was interpreted as relatively magnetite-rich formation $(\mathrm{L}, \mathrm{A})$ and was delineated as metasediments and granitoid (Older granite) respectively with reference to [6] The RTP image displays the highest magnetic intensity at the western part of the area (A in Fig. 4a and b.). These high magnetic anomalies are seen to trend in the NE -SW direction. Clear lithological boundaries are also observed in the image. These boundaries are observed from the sharp contrast in the magnetic signature on adjacent magnetic bodies. Some magnetic contrasts observed in Fig. 4 are interpreted as the lithological contacts. Prominent is the contact (Black line, in figure 4) between the Igarra meta-conglomerate and the quartzite (delineated as displayed by a fairly sharp magnetic contrast). The structures (F-F') and structures F-F and S-S' respectively represent likely faults and folds in the study area. Some magnetic contrasts observed in Fig. $4 \mathrm{~b}$ are interpreted as the lithological contacts. Prominent of this contact is at the western part marked A and D respectively

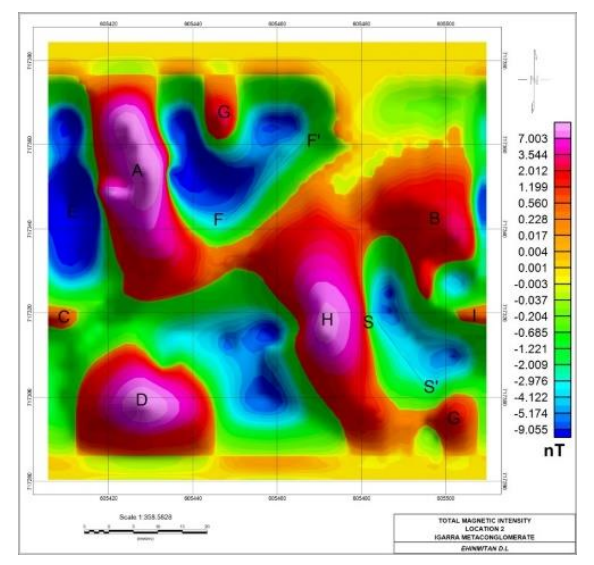

Figures 3 (a) and (b): Total magnetic intensity map showing areas of high and low magnetic intensity of location 1(A,B,C,D,E,H,I) 


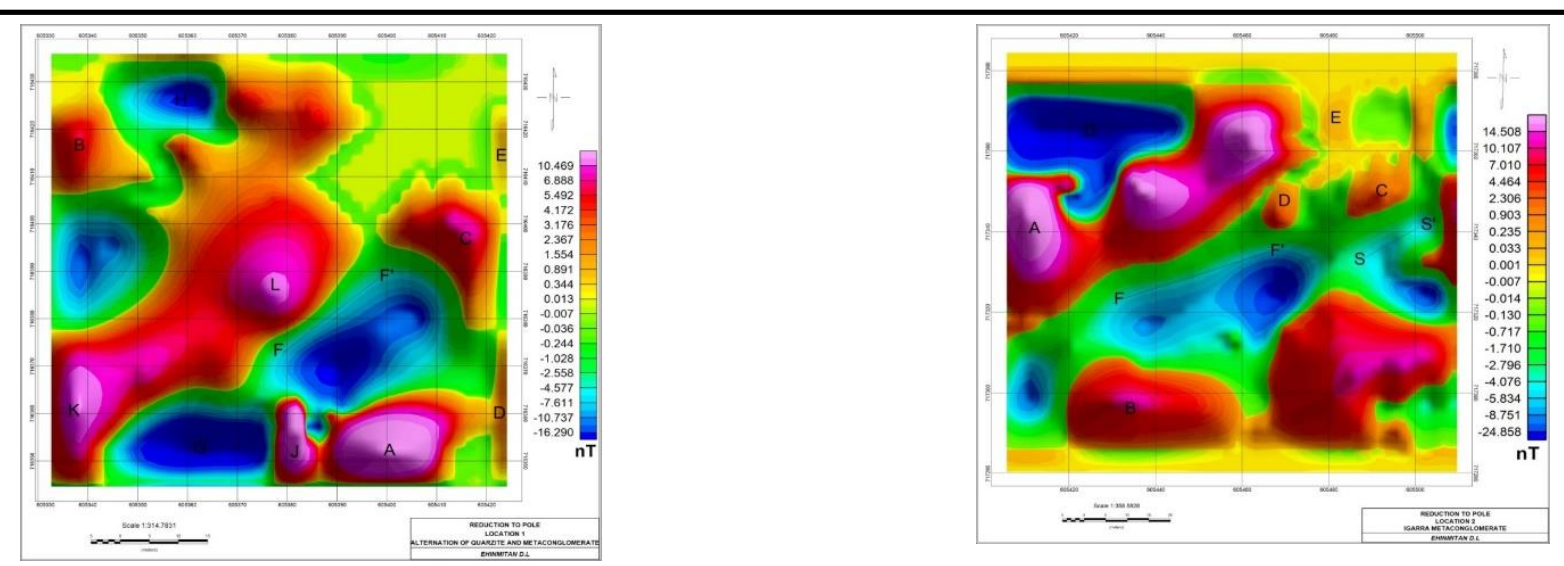

Figures 4 (a) and (b): Reduction to the pole (RTP) image

\subsection{Analytical signal}

The amplitude of the analytical signal can be related to the amplitude of magnetization. A group of scholars used the analytical signal of total magnetic intensities to delineate intermediary magmatic rocks in the Takab area of Iran [12].

Figure 5a and b (analytical signal map) shows that, the most prominent features are the high analytic signal amplitude that runs in an approximately north-south (NS) direction along the eastern and western border of the area respectively. Three major magnetic zones (high magnetic anomalous zone) define by (A), intermediate magnetic anomalous zone (marked with arrow) and low magnetic anomalous zone (F) and (E) ere delineated (Fig. 5a and b). The high magnetic signatures (A) of the analytical map suggests quartzite which are found around the south-eastern and north-western part of the area and trend in the northsouth direction as well as the high magnetic signatures (A) of the analytical may be likened to Migmatite basement complex (which is overlain by meta-sediment) and/or meta-conglomerate with reference to classification of magnetic susceptibilities of rocks (Fig. 5a and b) respectively [13]. Schistose quartzite is suspected to occur within the study area, and this schistose quartzite may responsible for the intermediate magnetic signature. The low magnetic signature was attributed to weathered quartzite, shale and sediments (F) (Fig. 5a and b).
In general, the analytical signal image (Fig. 5) revealed the different lithological units and geological structures in the area. The analytical signal map (Fig.5a.b) is also useful in the location of edges of magnetic source bodies particularly were remanence and / or low magnetic latitude complicates interpretation.

\subsection{First horizontal derivative}

To observe the near surface source magnetic features that are associated with geological structures, the first horizontal derivative filter was applied to the TMI grid. The color scale horizontal gradient images of the total magnetic intensity (Fig. 6a and b) enhanced the image by showing major structural and lithological detail which was not obvious in TMI image (Figure $3 \mathrm{a}$ and b). Geological structures were well delineated at (NW-SE and NE-SW) which might be considered a fault or fracture. In Figure $6 \mathrm{~b}$, the second vertical derivative map helps to highlight details and breaks in anomaly texture of near surface rocks i.e. subtle, local and short wavelength anomalies are emphasized. The short wavelength anomalies marked B, D, E, F and $\mathrm{H}$ on this map is caused by near surface small sized mineralized bodies and/or geological features. The reason why these anomalies are not seen in the original total magnetic ground map is because they have been obscured by stronger effect of broader regional features in the area. The NW-SE trending elongated low magnetic intensity anomaly marked $\mathrm{F}^{\prime}-\mathrm{F}$ at the west-east of the map is identified as a possible fault zone.
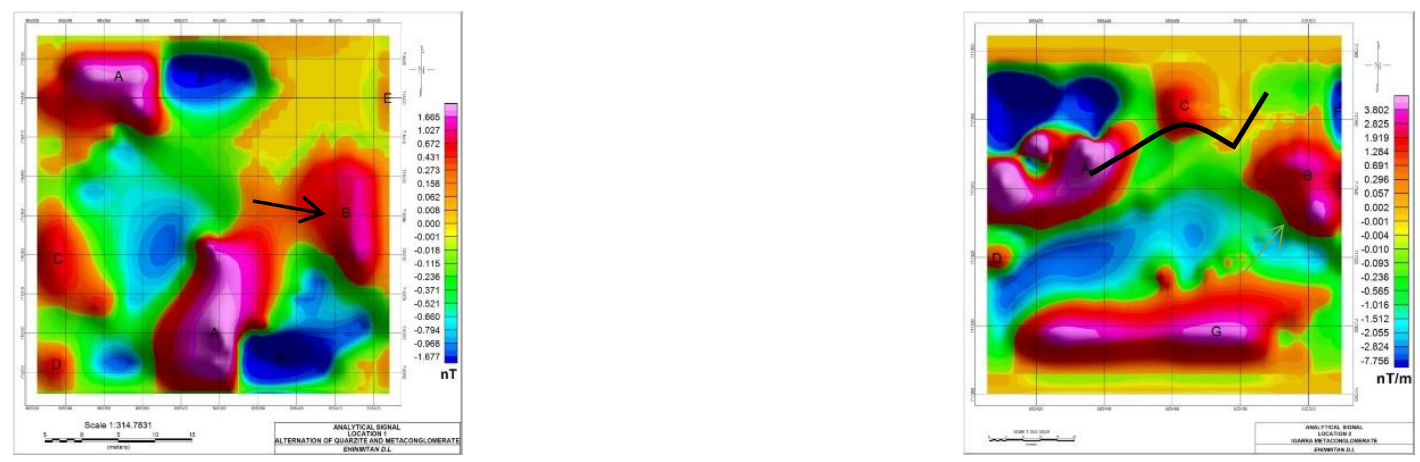

Figures 5 (a) and (b): Analytic signal image of total magnetic intensity
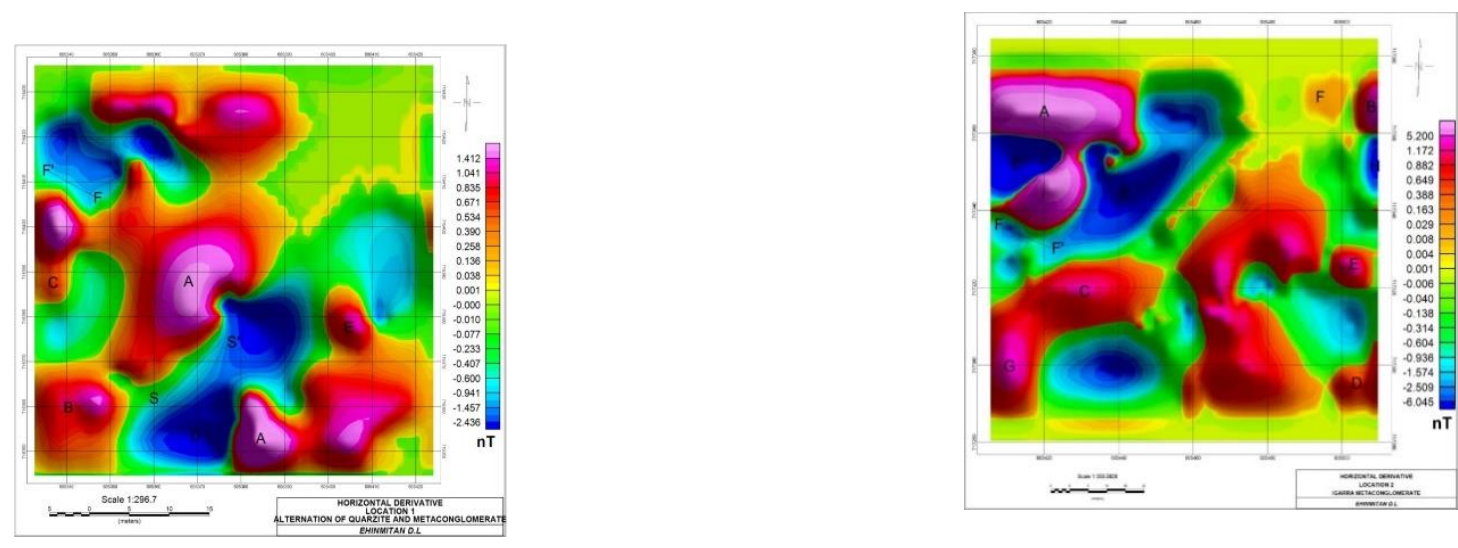

Figures 6 (a) and (b): First Horizontal derivative map of the TMI grid. 


\subsection{Upward continuation}

Figures 7 shows the RTP (grid) continued upward to $100 \mathrm{~m}$. The anomaly patterns identified in this map are a qualitative representation of spatial variation in the magnetic properties of deep basement rocks and structures in the area. There appears to be a good correlation in the trend of the low magnetic anomalies (F) in Figure 7 with those of the outcrops of the region (A, B, C and D). In physical terms, as the continuation distance is increased, the effects of smaller, narrower and thinner magnetic bodies progressively disappear relative to the effects of larger magnetic bodies of considerable depth extent. As a result, upward-continuation maps give the indications of the main tectonic and crustal blocks in an area.

\subsection{Tilt derivative}

Tilt angle derivative (TDR) of TMI locates the edges of formations, especially at shallow depths by using the theory that the zero contours are the edges of the formation. A scholar showed in their work that tilt derivative filter performs an automatic-gain-control (AGC) filter which tends to equalize the response from both weak and strong anomalies, hence, providing an effective way to trace out along striking anomalies [14]. It is observed that the zero contours estimate the location of abrupt changes in magnetic susceptibility values. The zero contour lines in this grid (Fig.8b and c) are represented by a yellow color. Figure 8a and c displays most structural feature of the area such as the faults, contacts and to some extent the shape of some lithology. Some lithologies (A, B, D and I) in the area are accentuated. Applying the filter on the RTP grid gave a clear picture of the magnetic body and structures in the area as compared to the filter applied on the TMI grid (comparing Fig.8a and Fig. 8b). The TDR image (Fig.8a \&8b) shows different lineaments and contacts in the area. Most of the lithological contacts in the area were delineated from the Fig. 8b (TDR on RTP image). Noticeable lithological contacts observed are; the quartzite-metaconglomerate contact marked with black lines. Faults (S-S, Q-Q') and folds (marked with pink color, F-F' and R-R'). At the western part of fig $8 \mathrm{~b}$, there exists quartzites represented by the intermediate magnetic intensity represented between the range $(0.419-$ $0.257 \mathrm{nT}$ ) which is said to occur at edges in the form of ridges with reference to. Some lithologies (e.g. A, B and E in Fig. 8c) in the area are accentuated.

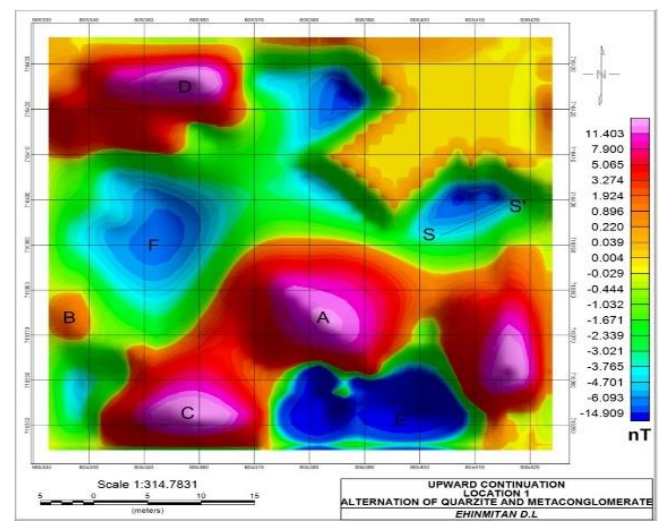

Figure 7: Upward continuation of location 1 traverse 1-3

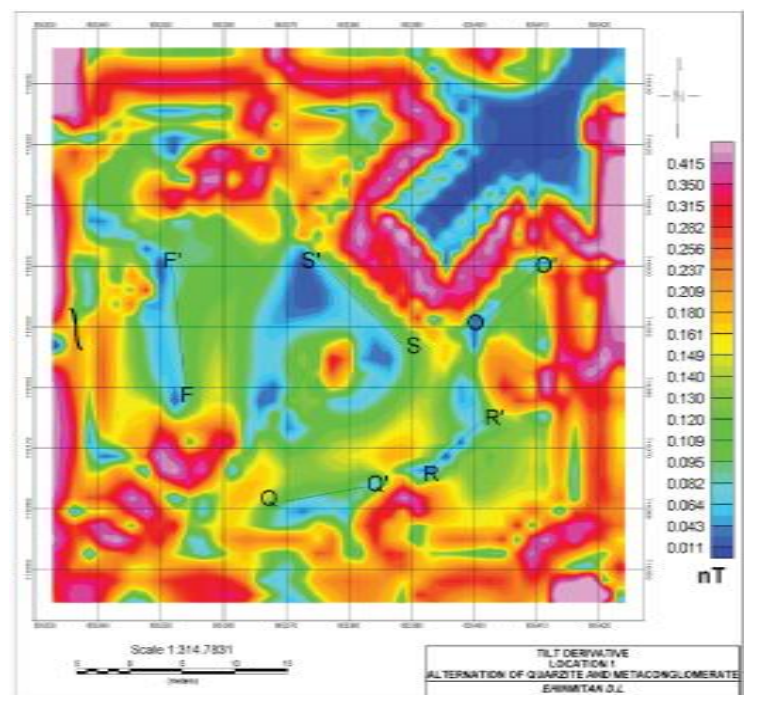

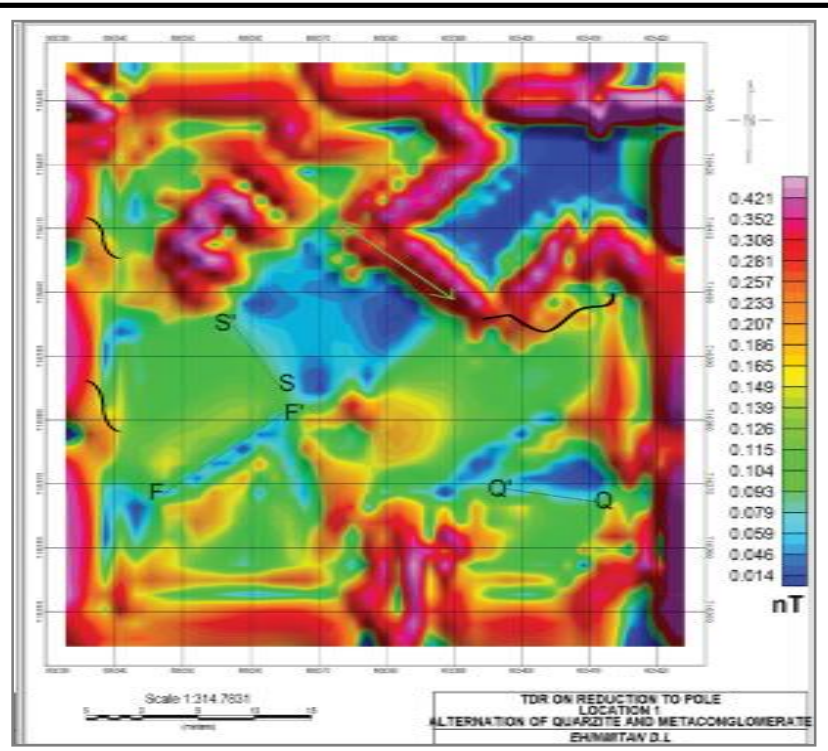

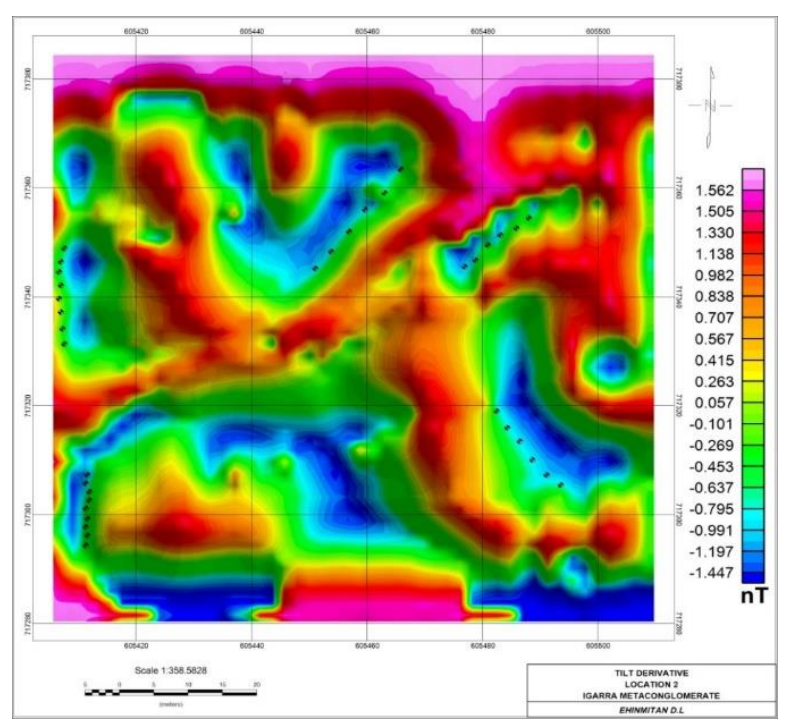

Figures 8 (a), (b) and (c): Tilt angle derivative, TDR (a) TDR derived from RTP image (b) TDR derived from TMI (c) tilt derivative of location 2.

\subsection{Euler 3D}

In this study, the Euler deconvolution algorithm in Oasis montaj (geophysical package) for location and depth determination of causative anomalous bodies. The Euler deconvolution as applied at each solution involves setting an appropriate structural index, SI value and using least squares inversion to solve the equation for an optimum $X_{0} Y_{0} Z_{0}$, and total magnetic field intensity (B). The window size and the respective number of the observation points, for which the system of linear equations is formed are also parameters in solving the inverse magnetic problem. Window of $10 \mathrm{x} 10 \mathrm{~m}$ data points prove most suitable in this study and were used. Solutions with depths to source above the error tolerance levels were rejected. The windowed Euler deconvolution solution points (Figure 9 and b) coincides weakly with regions having high analytic signal amplitude and therefore likely to represent regions with meaningful anomalies and they are in dikes model. Euler depth gave useful information about the subsurface topography of the Transition zone. The windowed Euler depth solutions have color coded circles, the circle's colors indicate depth range and the size defines depth variation within the range. Figure 9 shows the 3D Euler depths result of magnetic source ranged from $-92.595 \mathrm{~m}$ to $+73.95 \mathrm{~m}$ and $-115.45 \mathrm{~m}$ to $+57.44 \mathrm{~m}$ respectively.

\subsection{Radial average power spectrum}

The depths to the top of geologic sources that produced the observed anomalies in the magnetic map were determined using spectral analysis. The radially average power spectrum (Figure 10a and b) of both location $\mathrm{s}$ in the study area ground magnetic data shows a normal plot that has straight line segments which decreases in slope with increasing frequency. Peter's half slope was used to calculate the radial average spectrum, where $\mathrm{h}=0.63 \mathrm{~S}_{1 / 2}$. The result of Figure 10a shows that the depth to the top of the 
deeper magnetic source (outlined by slope 1) is $63 \mathrm{~m}$ with low magnetic intensity characterized by longer wavelength anomaly while most of the shallower sources (slope 2) is $44.1 \mathrm{~m}$ while figure $10 \mathrm{~b}$ shows that the depth to the top of the deeper magnetic source (outlined by slope 1) is $88.2 \mathrm{~m}$ with low magnetic intensity characterized by longer wavelength anomaly while most of the shallower sources (slope 2) is $81.9 \mathrm{~m}$ with anomaly of high magnetic intensity characterized by short wavelength anomaly.

The shallower sources probably depicted depths to Precambrian basement or near surface igneous intrusive rocks with remnant magnetism. The deeper sources were characterized by high negative anomaly values having longer wavelength and depicted basic intrusive rock at depth or intruding dike at depth.

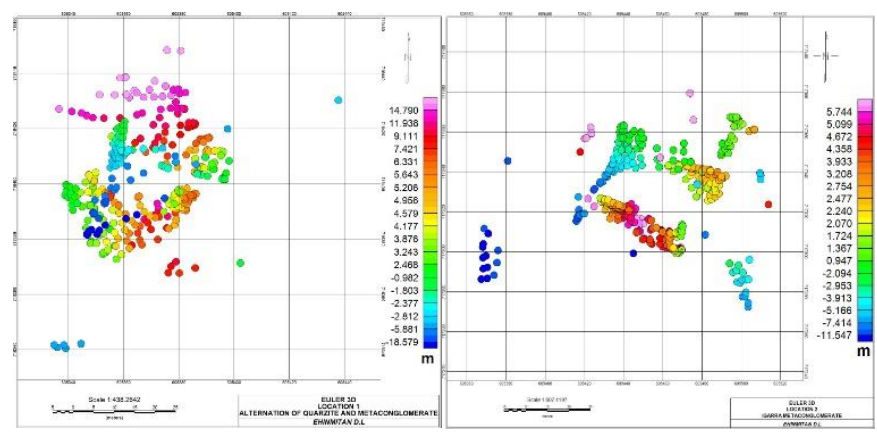

Figures 9 (a) and (b): Euler 3D for depth estimation of the study area
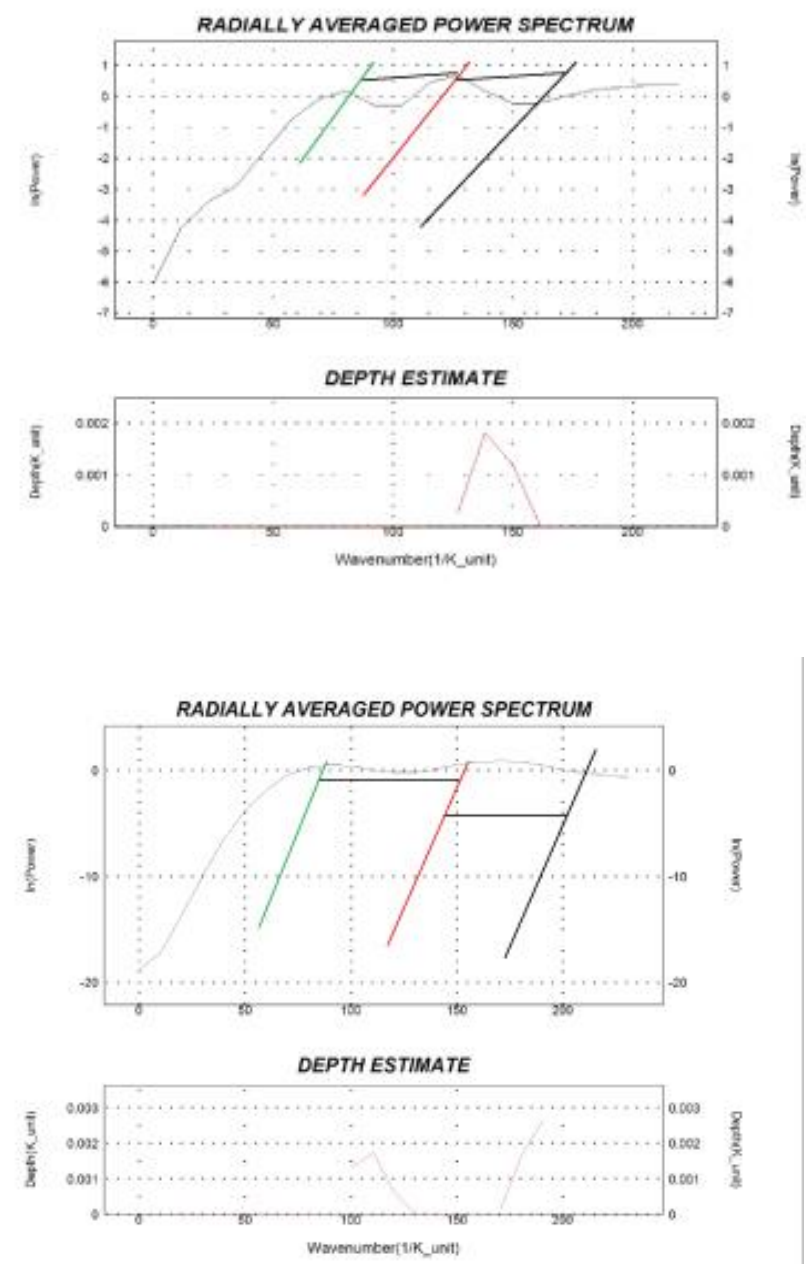

Figures 10 (a) and (b): The Radial Spectrum and Depth Estimate Plot of location 1 and 2 in the study area

\subsection{Radiometric maps}

\subsubsection{Location 1 and 2}

This location is suspected to consist of majorly quartz and metaconglomerate with shale. The data was processed using the Grid method of Geochemap and FFT2-D (Fast fourier transform) of Oasis montaj (Geophysical package).

\subsubsection{Potassium}

The potassium, K, map (Fig. 11a and b) shows different degrees of potassium concentrations that reflects different lithological units and alterations in the area. Potassium radiation fundamentally comes from potash feldspars, which are mainly common in felsic igneous rocks (e.g. granite) and are low in mafic rocks (e.g. basalts and andesite) [15]. Rock alterations can also result in high $\mathrm{K}$ concentrations. A number of potassium anomalies are evident in the radiometric image Fig. 11. The color blue corresponds with low K values whilst the pink corresponds with very high $\mathrm{K}$ values. The color red represents moderately high to high $\mathrm{K}$ values and the shades of orange to yellow color represent or are associated with moderately low $\mathrm{K}$ values.

Low potassium concentration is observed at the left side of the image and similar observation is seen at the upper left corner of the area (E, G, H, I). This observation coincides with the water body (Onyanmi river) present within the study area. Low concentration was recorded because water body shields the potassium radiation from the underlying rocks hence, reducing the intensity of the signal at that point. Since radiometric survey uses the assumption of residual of soil the top $30 \mathrm{~cm}$ soil is able to absorb most of the radiated radioactive element from the underlying rocks or the lithology. High concentration of $\mathrm{K}$ is also observed at the North-west and south-west corner (A in Fig. 11a) of the area. This coincides with the shale region mapped in the analytical signal map (Fig. 5) of the magnetic data. This shows that the shale in the area has high concentration of K. Similar observation at $(\mathrm{A}, \mathrm{J})$ of the area is seen at the western part of the area and this can also be attributed to shale. Figure $18 \mathrm{~b}$ shows the high potassium value (A, I, J) found in the North-west and South-east of the region is attributed to biotite- schist. This is because feldspar responsible for high potassium is present in biotite [16]. The moderately high potassium (B, C) in the North-south region correspond to metaconglomerate while low potassium represented by the yellow colour (D) may be attributed to gneiss.

\subsubsection{Thorium}

Anomalies in the thorium data in Fig.19 helped map the lithology and lithological boundaries of the area. The thorium, Th map shows three distinct regions of thorium concentration in the area. These Th concentration zones are represented by pink color, relatively high concentration of the Th concentration represented by green color and low Th concentration represented by blue color (Fig.12). The high concentration in Th depicted (A) (Fig.12a) correspond to shale, schist and other weathered sediment (clast) in the area. These weathered sediments as well as quartzite are believed to have originated from the rock (sandstone) in the high elevated lands in the region. The assertion coincides with the high elevated lands in the area (Fig: 1b). In addition, the low concentration of Th (E) observed at the western part of the area coincides with the weathered rocks in the area. This indicates the fact that the water body shield the emission of radiation from radiogenic element (thorium) of the underlying lithology.

The high concentration in Th depicted (A) (Fig. 12b) correspond to metaconglomerate and other weathered sediment/rocks in the area. These weathered sediments are believed to have originated from the rock sandstone which was later metamorphosed to quartzite. Moreover, the low concentration of Th $(\mathrm{G}, \mathrm{H})$ observed at the North-South part of the area coincides with the biotite-schist and weathered sediments in the area. This indicates the fact that the water body shield the emission of radiation from radiogenic element (thorium) of the underlying lithology. There appears to be a contact (A, G, I) biotite gneiss banded with meta-conglomerate at the bottom left corner (SW) of the map. Also noticeable on the map is a fault line (F-F' and Q-Q') trending north-south of the study area.

Though radiometric method to some extent is limited in the use for structural mapping and that its main use is for mapping lithological units and alterations by determining the spatial correlation existing between the radiometric data and the rocks. Interestingly there appears to be a fault line (-3.843 to $-1.275 \mathrm{ppm})$ trending towards the South-eastern part of the study area. This validates its application as a useful tool for geological mapping. 

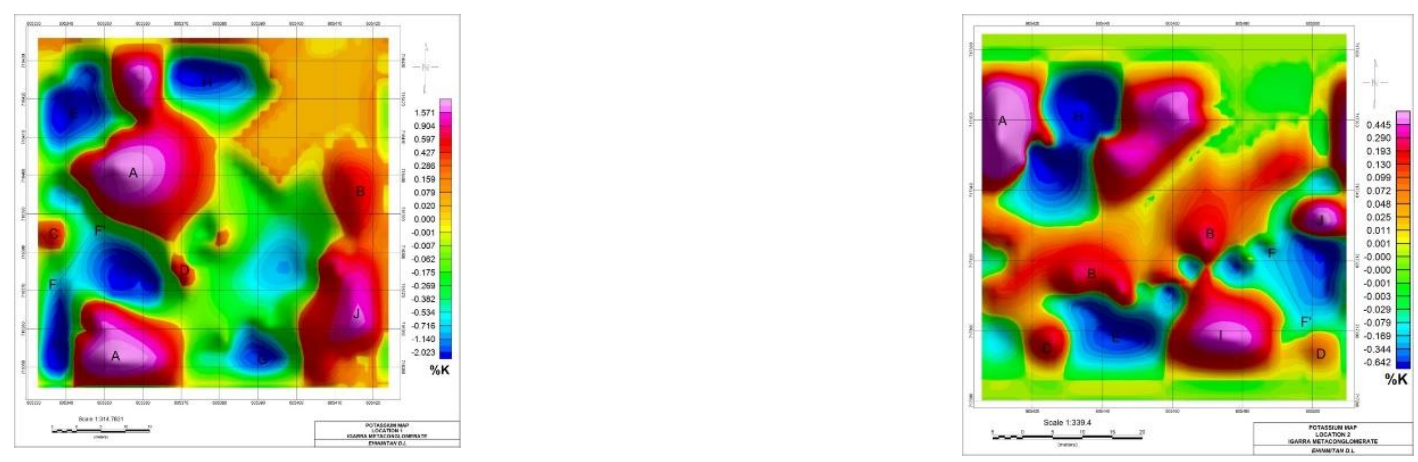

Figures 11 (a) and (b): Gamma spectrometric image for Potassium (K) concentration respectively.
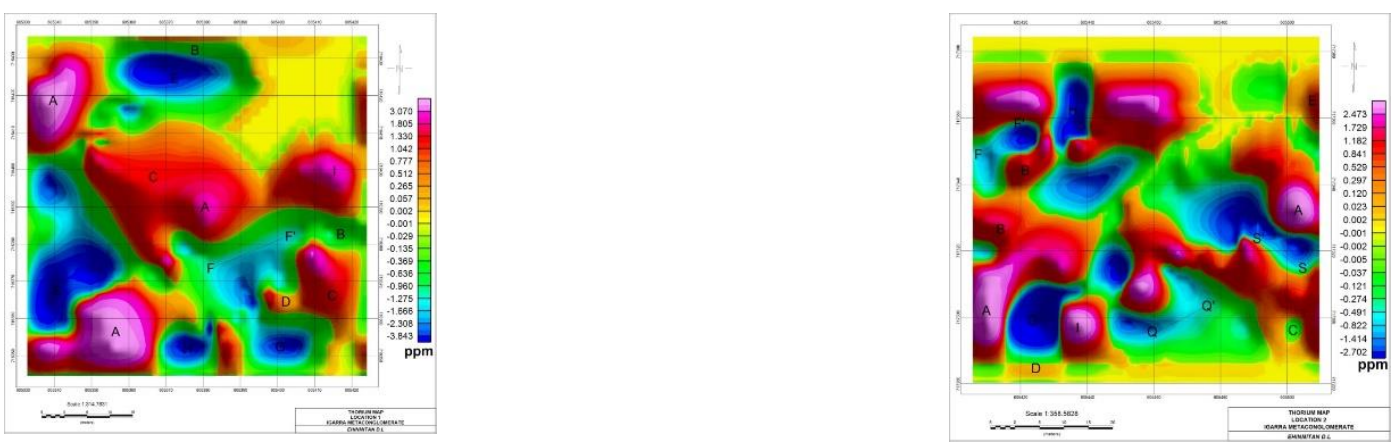

Figures 12 (a) and (b): Gamma spectrometric image for thorium (eTh) concentration respectively.

\subsubsection{Uranium}

The uranium image shows good definition in mapping of weathered rocks (radiogenic pattern D in (Fig. 13) and certain radiogenic rock pattern A, B and $\mathrm{C}$. The feature $\mathrm{A}$ is registered high uranium concentration. High concentration of uranium is also observed at the North-west and Southwest part of the area. This feature coincides with sediments within the Benin flank of Anambra basin. Unlike the K and the Th maps, the uranium; $\mathrm{U}$ map could not clearly delineate the distinct boundary between most of the lithology of the area. Around the NE-SW, (F-F') area of thorium image there is noticeably a fault line having $(-2.023$ to $-0.716 \mathrm{ppm})$ trending in the North-South part of the study area and (S-S') trending E-W.

The uranium image shows good definition in mapping of biotite-schist and weathered sediments (radiogenic pattern D and $\mathrm{H}$ in Fig. 13b) and certain radiogenic rock pattern $\mathrm{A}, \mathrm{B}$ and $\mathrm{G}$. The feature $\mathrm{A}$ is registered high uranium concentration. High concentration of uranium is also observed at the North-west and South-west part of the area. This feature coincides with shale in the area. Thus, the shale is broadly represented by high $\mathrm{U}$ concentration (A in Fig. 13b). Unlike the K and the Th maps, the uranium, $\mathrm{U}$ map could not clearly delineate the distinct boundary between most of the lithology of the area. At eastern part of the map in (fig. 13b), there exists noticeable halos. This halo is attributed to weathering in that region. Weathering decreases the U/TH ratio in weathered rock and it leads to dispersion halos, particularly in the case of uranium that extend over a much greater area than does the parent formation. This validates its application of radiometric method as a useful tool for geological mapping. The obvious boundary between the quartzite and the meta-conglomerate which are clearly seen in the Th map (Fig. 11) and Potassium map (Fig. 12) was not observed the uranium map. This is because the image (Fig. 20) shows short wavelength anomalies corresponding to noise caused by the variations in atmospheric radon concentrations during the course of the survey resulting in significant streaking in the image. This is a typical feature found in uranium images, in spite of the processing steps the dataset was subjected to.

\section{TERNARY MAP}

The radiometric data are displayed as a ternary map with combined intensities of potassium (K), thorium (Th), uranium (U) concentration given in red, green, and blue color respectively. The ternary radiometric map (Fig. 14a and b) shows different color combinations which indicate the $\mathrm{K}, \mathrm{Th}$ and $\mathrm{U}$ concentrations [17]. The radiometric responses in the ternary map, to some extent, correspond with the surface geological map of the study area (Fig. 2). Low concentrations of $\mathrm{U}$, Th, and $\mathrm{K}$ radioactive elements are displayed by black colors with the magenta color corresponding to high potassium with low uranium and thorium concentrations. Those with the low content of $\mathrm{K}$ but high contents of $\mathrm{U}$ and Th are characterized by green color and the yellow colors are characterized by high potassium and thorium with low uranium. Additionally, the blue color corresponds to regions of high uranium with low potassium and thorium and white color corresponds to high potassium, uranium and thorium.

From the ternary map, the weathered rock can easily be delineated as having low concentration of the three radiogenic elements (depicted by a black color in Fig. 14a). The contact between the quartzite and metaconglomerate (E and C in Fig. 14a) in the area is also observed. The high concentration of $\mathrm{K}$, Th and $\mathrm{U}$, at top left corner of west part of the image suggest an intrusion possibly granitic intrusion within the Benin flank of Anambra basin. The high $\mathrm{K}$ with low $\mathrm{U}$ and $\mathrm{Th}$ concentration which is depicted by a magenta color coincides with low grade metamorphosed rock in the area. Blue color corresponds to regions of high uranium with low potassium and thorium coincides with sediments in the area and it's the most widely spread outcrop in this location [18-21].

From the ternary map, the weathered rock was delineated as having low concentration of the three radiogenic elements (depicted by a black color in Fig. 14b). The high concentration of K, Th and U (A) of west part of the image coincides with granitic intrusion in the area. The high $\mathrm{K}$ with low $\mathrm{U}$ and Th concentration which is depicted by a magenta color coincides with shale. Blue color corresponds to regions of high uranium with low potassium and thorium which may be attributed to schist in the area.

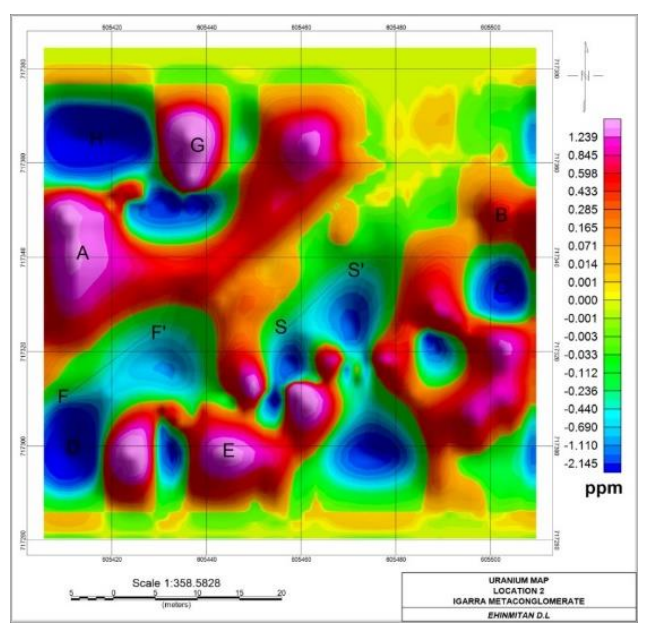




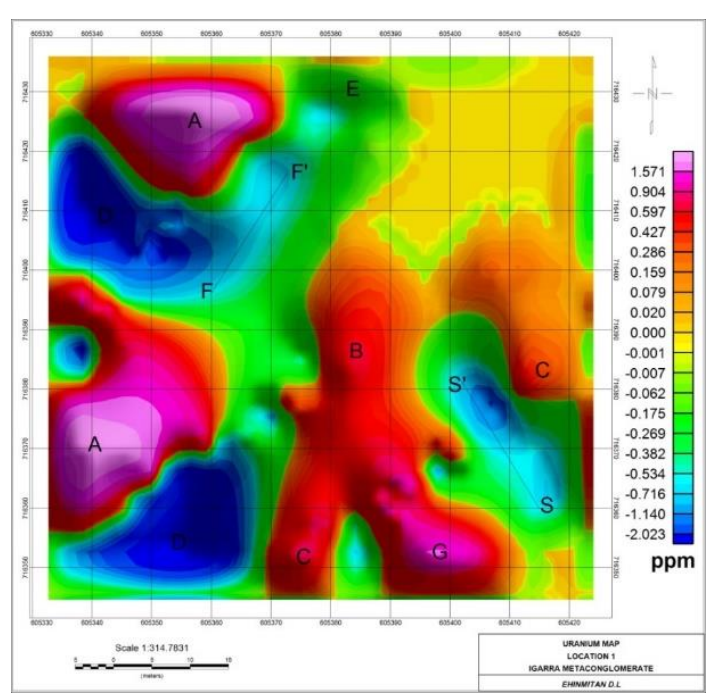

Figures 13 (a) and (b): Gamma spectrometric image for Uranium (eU) concentration respectively.
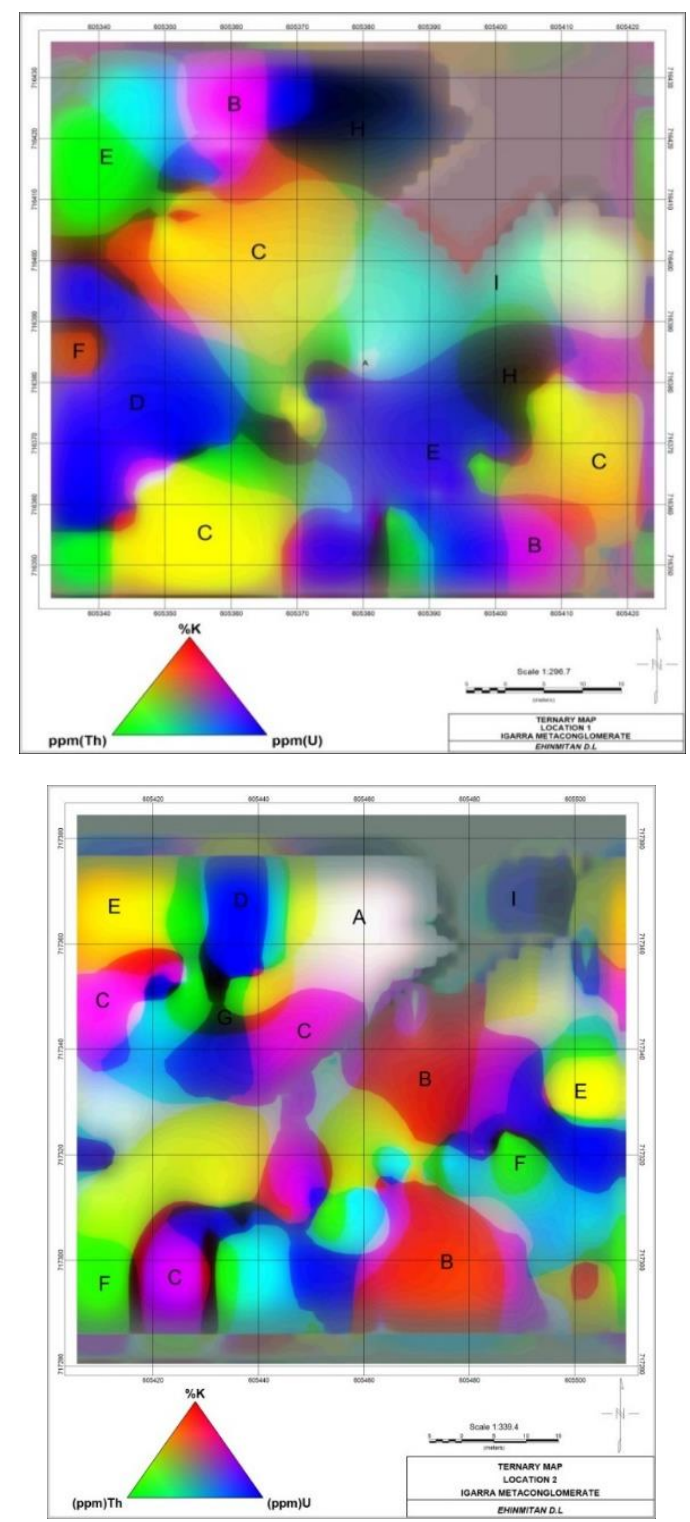

Figures 14 (a) and (b): Ternary maps of Study area for location 1and 2 $(\mathrm{RGB}=\mathrm{KThU})$ respectively.

\section{QUANTITATIVE INTERPRETATION}

Attempt was made to estimate the depth to basement of the magnetic body. The Geosoft oasis montaj Depth to Basement extension which determines the position (distance along the profile and depth), dip (orientation) and intensity (susceptibility) of magnetic source bodies for a magnetic profile was used. The Werner deconvolution function which uses the horizontal and vertical derivatives in the calculation in the depth to basement of the magnetic anomaly was employed. It assumes the source bodies are either dikes or contacts with infinite depth extent and uses a least-squares approach to solve for the source body. Six profiles were chosen across the total magnetic intensity map of the area to estimate the depth to magnetic bodies and possibly the intensity (susceptibility). The profiles were plotted and displayed (Fig. 15-20). Two depth source models (Dike and contacts model) were assumed and their depths to basement were estimated using the Werner deconvolution function. The dike model fits the description of depth in the study area.

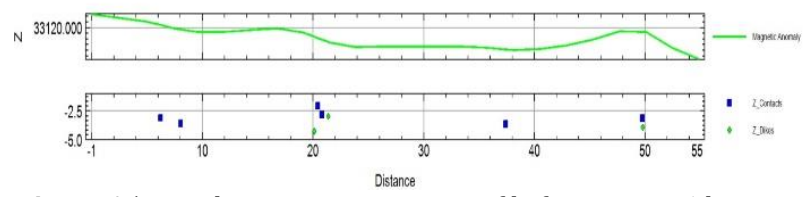

Figure 15: Total magnetic intensity profile for traverse 1 location1

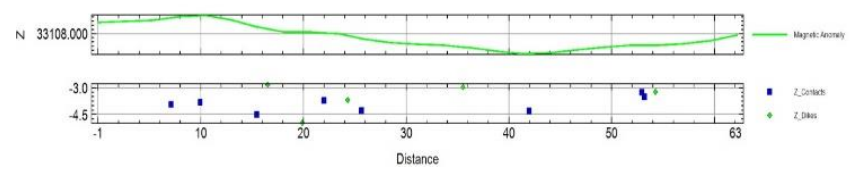

Figure 16: Total magnetic intensity profile for traverse 2 location1

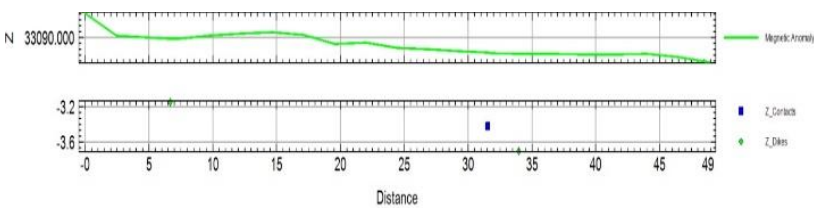

Figure 17: Total magnetic intensity profile for traverse 3 location1.

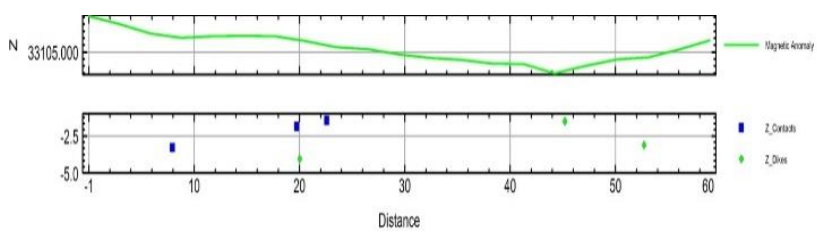

Figure 18: Total magnetic intensity profile for traverse 1 location 2

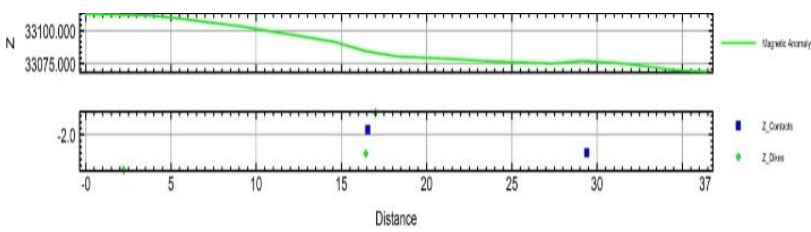

Figure 19: Total magnetic intensity profile for traverse 2 location 2

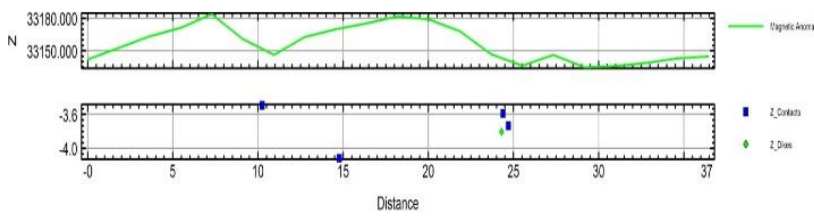

Figure 20: Total magnetic intensity profile for traverse 3 location 2

\section{CONCLUSION}

In order to map out the lithology and geological structures of the study area, ground radiometric and magnetic datasets collected over the area were processed and enhanced. The magnetic image enhancing filters applied to the total magnetic intensity (TMI) using Geosoft (Oasis Montaj) are reduction to the pole (RTP), analytic signal, first vertical derivative (1VD), first horizontal derivative, Tilt derivative (TDR) and upward continuation (UC). These filters helped define the lithological boundaries, intersection of geological structures, faults, folds and contacts. The tilt derivative (TDR) proved very useful in the delineation of the contacts and the most of geological structures in the area. The radiometric data provided geochemical information of uranium $(\mathrm{U})$, thorium and potassium $(\mathrm{K})$ and proved valuable in delineating bedrock lithology of the area such as the shale, quartzite, schist and meta-sediment and to extent geological structure. The radiometric dataset was also valuable in the detecting the response of water body (Onyanmi river) within the study area and the lithological contacts of the various rock formations. The interpretation of the high-resolution ground magnetic dataset has provided a synopsis of the regional geology (lithology) as well as further insight into structural 
controls of the area. It also shows a detailed assessment of various lithology and north-south striking of the geology in the area. The metasediments (meta-conglomerate and schists) are the oldest and form the country rocks which the granites intruded. Interpretation of magnetic and radiometric data based on the mineralogical and structural evidence of the study area suggest that they were formed from low grade regional metamorphism of argillaceous sediments such as shales or sediments of varying composition. The foliation trend of the study area in the NW- SE and NE-SW observed on the magnetic map suggests that the study area must have undergone tectonic activity. Tectonic effects are further indicated by the presence of folds observed in the tilt angle derivative map. 3D Euler deconvolution and Average radial spectrum were adopted to estimate the depth of the magnetic sources which ranges from $-92.895 \mathrm{~m}$ to $73.95 \mathrm{~m} ;-115.45 \mathrm{~m}$ to $57.44 \mathrm{~m}$ and $63 \mathrm{~m}$ to $44.1 \mathrm{~m} ; 88.2 \mathrm{~m}$ to $81.9 \mathrm{~m}$ respectively. The depth to basement of the formations within the study area was determined using the contact model and the dike models. The contact model produced shallow depth while the dike model on the other hand produced depth for the basement rock. This is because dike model anomaly occurs at a greater depth than the contact model. The dike model seems to best fit the study area. The magnetic dataset proved valuable in the delineation of most of the lithologies and structures in the area and estimating the depth to basement of the magnetic body with the radiometric dataset proving to be a valuable tool for mapping lithology and water bodies.

\section{REFERENCES}

[1] Nettleton, L.L. 1976. Gravity and Magnetics in oil prospecting. McGrawHill, New York, 394-413.

[2] Folami, S. 1992. Interpretation of Aero magnetic Anomalies in Iwaraja area, Southwestern Nigeria, Journal of Mining and Geology, 28, (2), 391396.

[3] Kowalik, W.S., Glenn, W.E. 1987. Image processing of aeromagnetic data and integration with landsat images for improved structural interpretation. Geophysics 53, 875-884.

[4] Barker, R.D., White, C.C., Houston, J.F.T., 1992, Borehole siting in an African accelerated drought relief project. In: Hydrogeology of Crystalline Basement Aquifers in Africa, Geological Society Special Publication, 66, 183-201.

[5] Faure, G. 1977. Principles of Isotope Geology. UK: John Willy and Sons Inc. 331.

[6] Odeyemi, I.B. 1976. Preliminary report on the field relationships of Basement complex rocks around Igarra, Mid-Western State, Nigeria: Geology of Nigeria. University of Ife, Nigeria.

[7] Odeyemi, I.B. 1988. Lithostratigraphy and structural relationships of the Upper Precambrian Metasediments in Igarra area, southwestern Nigeria.
[8] Riddihoug, R.P. 1971. Diurnal correction to magnetic survey - An assessment of errors. Geophysical Prospecting 19(4), 551-567.

[9] Breiner, S. 1999. Application manual for portable magnetometer. Geometrics, California, USA, 1-58

[10] Silva, A., Pires, A., Mccafferty, A., De Moraes, R., Xia, H. 2003 Application of Airborne Geophysical Data to Mineral Exploration in the Uneven Exposed Terrains of the Rio Das Velhas Greenstone Belt. Revista Brasileira de Geociências, 33, 17-28.

[11] Ostrovskiy, E. 1975. Antagonism of radioactive elements in wallrock alteration fields and its use in aerogamma spectrometric prospecting. International Geology Review, 17(4), 461-468.

[12] Asadi, H., Hale, M. 1999. Integrated analysis of aeromagnetic, landsat TM and mineral occurrence data for epithermal gold exploration in Northwest-Iran. 13th International Conference on Applied Geologic Remote Sensing, Vancouver. British Columbia.

[13] Telford, W., Gelbert, I., Sheritt, R. 1990. Applied Geophysics. London: Cambridge University Press.

[14] Verduzco, B., Fairhead, J., Green, C., Mackenzie, C. 2004. New insights into magnetic derivatives for structural mapping. The Leading Edge, 23 , 116-119.

[15] Gunn, P., Maidment, D., Milligan, P. 1997a. Interpreting aeromagnetic data in areas of limited outcrop. AGSO Journal of Australian Geology \& Geophysics, 17(2), 175-185.

[16] Gunn, P., Minty, B., Milligan, P. 1997b, The Airborne Gamma-Ray Spectrometric Response Over Arid Australian Terranes. Proceedings of Exploration 97: Fourth Decennial International Conference on Mineral Exploration, 733-740. Australia.

[17] Afenya, P. 1982. Ghana's mineral resources for small-scale mining industries. Strategies for small-scale mining and mineral industries, 8, 2428.

[18] Foss, C. 2011. Magnetic data Enhancement and Depth Estimation. Encyclopedia of Earth Sciences Series, 736-746.

[19] Grant, F., Martin, L. 1966. Interpretation theory in applied Geophysics. New York: McGraw-Hill Book Co.

[20] Murphy, B. 2007. Airborne geophysics and the Indian scenario Journal of Indian Geophysics, 11(1), 1-28.

[21] Roy, A. 1966. The method of continuation in mining geophysics. Geoexploration, 4, 65-83. 